\title{
EDUCAÇÃO DE ADULTOS EM PORTUGAL E NO BRASIL: APROXIMAÇÕES E DISTANCIAMENTOS
}

\author{
M. M. MACHADO \\ Universidade Federal de Goiás \\ mmm2404@gmail.com
}

Submetido 14/08/2017 - Aceito 22/05/2018

DOI: $10.15628 /$ holos.2018.6978

\section{RESUMO}

O objetivo deste texto é discutir sobre educação de adultos em Portugal e no Brasil. No caso específico do Brasil, abordarei sobre o Programa Nacional de
Integração da Educação Profissional com a Educação Básica, na modalidade de Educação de Jovens e Adultos (Proeja) nos institutos federais, em tempos de implantação da Reforma do Ensino Médio.

PALAVRAS-CHAVE: Educação profissional, Ensino Médio, Educação de Adultos, Brasil, Portugal

\section{ADULT EDUCATION IN PORTUGAL AND BRAZIL: APPROACHES AND DISTANCES}

\section{ABSTRACT}

The purpose of this article is to discuss adult education in Portugal and Brazil. In the specific case of Brazil, the National Program for the Integration of Professional Education with Basic Education in the modality of Youth and Adult Education (Proeja) will be approached in federal institutes, at times of implementation of the High School Reform.

KEYWORDS: Profissional education, High School, Adult Education, Brasil, Portugal. 


\section{INTRODUÇÃO}

Ser livre é dar-se um destino ( José Barata-Moura)

Esta reflexão resultou do diálogo na mesa compartilhada com Rosanna Barros da Universidade do Algarve e Ana Henrique do Instituto Federal do Rio Grande do Norte (IFRN), tratando da temática Educação de Adultos em Portugal e no Brasil. Voltar a este instituto e reencontrar todos os colegas pesquisadores neste IV Colóquio Nacional e I Internacional A Produção do Conhecimento em Educação Profissional - A reforma do ensino médio (Lei 13.415/2017) e suas implicações para a educação profissional, é sempre um enorme prazer e me traz a cada ano um desafio que é o de contribuir de fato com as reflexões que me propõem seus organizadores. Nesse ano, fico ainda mais à vontade por voltar a falar de um tema que me acompanha, nos últimos trinta anos de trabalho, que é a Educação de Jovens e Adultos, aqui num tratamento com um recorte para a realidade do adulto.

Tomo de empréstimo as reflexões suscitadas pelas atividades realizadas na abertura do evento, para introduzir esse texto, começando pelo teatro representado pelos jovens do Instituto Federal do Rio Grande do Norte, Campus São Paulo do Potengi, que nos deixou a pergunta: o que de fato é a liberdade? Para em seguida, tomar da Conferência de Abertura, proferida pelo Professor José Barata-Moura, a resposta à pergunta formulada pelos jovens: Ser livre é dar-se um destino, ou seja, constituir-se como sujeito autônomo. Creio que os quatro dias de eventos foram tocados por essa mensagem e o que todos tentamos realizar em nossas reflexões foi essa busca de dar sentido ou retomá-lo em nossas lutas no campo da educação, em particular frente aos inúmeros desafios que a conjuntura política brasileira nos impõe, sobretudo diante da atual reforma do Ensino Médio. Refletimos sobre o papel fundamental da educação para a tarefa de dar-se um sentido, pois não é possível pensar em autonomia sem o conhecimento. Um lugar privilegiado para a acesso e produção de conhecimentos deve ser a escola. Não é o espaço exclusivo, mas é um espaço importante e necessário.

Desejo esclarecer que não conheço com propriedade a realidade da educação de adultos em Portugal, portanto, aprendi muito com a exposição da Professora Rosanna Barros e percebi quantas aproximações temos nas iniciativas em Educação de Adultos, a partir de sua exposição com inúmeros esclarecimentos históricos. Da mesma forma, compartilho das angústias e dúvidas 
apresentadas por Ana Henrique, acerca do destino do Programa Nacional de Integração da Educação Profissional com a Educação Básica, na modalidade de Educação de Jovens e Adultos (Proeja) nos institutos federais, em tempos de implantação da Reforma do Ensino Médio. Esse programa vinha, na última década, se revelando como uma importante oportunidade para jovens e adultos retornarem ao processo de escolarização, numa proposta de currículo que integra a formação geral e a formação profissional.

A sistematização da experiência compartilhada no colóquio será apresentada, nesse artigo, iniciando por um diálogo com a questão do conceito de educação de adultos e suas especificidades diante de realidades tão diferentes no mundo, explicitando a opção de utilização da terminologia Educação de Jovens e Adultos (EJA), no Brasil. Em seguida, retomamos parte da história da educação de adultos desse país, com o suporte de vários de seus importantes atores e autores, dentre eles Lemme (2004), Beisiegel (2004), Fávero (2015), Paiva (2003), Freire (1967, 1981, 1983, 1987, 1989, 1996, 2001). Finalizamos a reflexão convidando a todos para continuar pensando sobre o que já foi feito e o quanto ainda necessitamos fazer para que de fato jovens e adultos tenham o direito de acesso a educação.

\section{DO QUE MESMO ESTOU FALANDO QUANDO TRATO DA EDUCAÇÃO DE ADULTOS}

As publicações internacionais sobre o conceito de Educação de Adultos, contribuem para fazer uma distinção entre o que compreendo ser necessário frisar sobre a educação de adultos no Brasil, no atual contexto, e a forma como essa temática é considerada no âmbito de organismos internacionais que representam seus estados-membros, mais especificamente a Organização das Nações Unidades para a Educação, a Ciência e a Cultura (Unesco) e a Organização dos Estados Iberoamericanos (OEI).

A última Conferência Internacional de Educação de Adultos (VI Confintea), promovida pela Unesco, tendo como sede o Brasil, publicou em seu documento final, o Marco de Belém, a seguinte consideração sobre educação de adultos,

[...] a educação de adultos engloba todo processo de aprendizagem, formal ou informal, em que pessoas consideradas adultas pela sociedade desenvolvem suas capacidades, enriquecem seu conhecimento e aperfeiçoam suas qualificações técnicas e profissionais, ou as redirecionam, para atender suas necessidades e as de sua sociedade. (UNESCO, 2010, p.5) 
Esse conceito de Educação de Adultos é abrangente e tem sido tratado, em muitos países, como educação ao longo da vida, que incorpora inclusive iniciativas como esta da qual estamos participando nesse evento, onde a programação toda se pauta pela troca de saberes e experiências entre pesquisadores, o que nos coloca em condição de aprendentes e ensinantes. Mas, a realidade do Brasil e de muitos países da América Latina, África e Ásia, exige de nós, pesquisadores da Educação de Adultos, um cuidado a mais com esse conceito.

Não podemos considerá-lo apenas na perspectiva da educação permanente, que é da própria condição humana, sem destacar a negação do direito a educação básica que ainda persiste em nossos países. Sem reconhecer os limites históricos que a nossos países foram impostos pelos processos de colonização, sobretudo quando a esse se conjuga séculos de escravatura, como no caso brasileiro. Sobre essa questão, Darcy Ribeiro, assim afirma,

Nenhum povo que passasse por isso [o período da escravidão] como sua rotina de vida através de séculos sairia dela sem ficar marcado indelevelmente. Todos nós brasileiros somos carne da carne daqueles pretos e índios supliciados. Todos nós brasileiros somos, por igual, a mão possessa que os supliciou. A doçura mais terna e a crueldade mais atroz aqui se conjugaram para fazer de nós a gente sentida e sofrida que somos e a gente insensível e brutal que também somos. (RIBEIRO, 1995, p.120)

Para aqueles que acompanharam a fala da Professora Maria Ciavatta, nesse IV Colóquio, perceberam o quanto a história do trabalho e dos trabalhadores no Brasil está intimamente marcada pelos processos de colonização e o peso da escravização dos homens e mulheres que construíram e constroem esse país. Cury (2010), ainda em relação aos países submetidos a esse modelo de colonização, esclarece que,

[...] Neles, à desigualdade se soma a herança de preconceitos e de discriminações étnicas e de gênero incompatíveis com os direitos civis. Em muitos desses países, a formalização de conquistas sociais em lei e em direito não chegam a se efetivar por causa desses constrangimentos herdados do passado e ainda presentes nas sociedades. (...)

A escravidão, o caráter agrário-exportador desses países e uma visão preconceituosa com relação ao "outro" determinaram uma estratificação social de caráter hierárquico. Nela, o outro não era visto como igual, mas como "inferior". Logicamente as elites atrasadas desses países tendo-se na conta de "superiores" determinaram o pouco peso atribuído à educação escolar pública para todos. (p. 113)

Este debate do Professor Jamil Cury repondo a questão do direito à educação nos orienta na reflexão que faremos na tentativa de destacar da história da educação brasileira o lugar do debate e das políticas para educação de adultos, enquanto direito à escolarização, não desprezando os inúmeros espaços formativos aos quais esses sujeitos adultos devem ter acesso, 
mas dada a realidade de baixa escolaridade da população de 15 anos e mais no Brasil, consideramos fundamental reiterar nessa discussão a importância dos conhecimentos produzidos, sistematizados e socializados pela escola na vida de jovens e adultos trabalhadores.

$\mathrm{O}$ direito à educação parte do reconhecimento de que o saber sistemático é mais do que uma importante herança cultural. Como parte da herança cultural, o cidadão torna-se capaz de se apossar de padrões cognitivos e formativos pelos quais têm maiores possibilidades de participar dos destinos de sua sociedade e colaborar na sua transformação. Ter o domínio de conhecimentos sistemáticos é também um patamar sine qua non a fim de poder alargar o campo e o horizonte desses e de novos conhecimentos. (Cury, 2010, p. 116)

Portanto, as reflexões sobre pensar a educação de adultos no Brasil, com o viés da escolarização básica, ou melhor, a partir da defasagem dessa escolarização, parte da convicção de que estamos falando de uma questão de direito ainda não efetivado, como comprovam os dados que serão apresentados a seguir que fazem parte do documento brasileiro que avalia a realidade no país, passados seis anos da realização da VI Conferência Internacional de Educação de Adultos (VI Confintea), no Brasil, em 2010. Portanto, são dados produzidos oficialmente e que revelam a própria dificuldade que no Brasil temos de fazer com que os nossos discursos e compromissos se materializem na prática.

Tabela 1 - Analfabetismo e analfabetismo funcional da população com

15 anos ou mais - 2014

\begin{tabular}{|c|c|c|c|c|c|c|c|}
\hline & \multirow[b]{2}{*}{2014} & \multicolumn{4}{|c|}{ Analfabetismo } & \multicolumn{2}{|c|}{ Analfabetismo funcional } \\
\hline & & Total & $\begin{array}{l}\text { Sabe lere } \\
\text { escrever }\end{array}$ & $\begin{array}{l}\text { Não sabe } \\
\text { ler } \\
\text { e escrever }\end{array}$ & $\begin{array}{c}\% \text { de } \\
\text { analfabetismo }\end{array}$ & $\begin{array}{c}\text { Total } \\
\text { analfabetos } \\
\text { funcionais }\end{array}$ & $\begin{array}{c}\% \text { de } \\
\text { analfabetismo } \\
\text { funcional }\end{array}$ \\
\hline \multirow{6}{*}{ Regiões } & Total Brasil & 159.243 .370 & 146.073 .028 & 13.170 .342 & 8,3 & 28.029 .368 & 17,6 \\
\hline & Norte & 12.463 .858 & 11.345 .448 & 1.118 .410 & 9,0 & 2.545 .484 & 20,4 \\
\hline & Nordeste & 42.856 .546 & 35.736 .057 & 7.120 .489 & 16,6 & 11.631 .254 & 27,1 \\
\hline & Sudeste & 68.652 .311 & 65.513 .327 & 3.138 .984 & 4,6 & 8.721 .440 & 12,7 \\
\hline & Sul & 23.414 .546 & 22.387 .419 & 1.027 .127 & 4,4 & 3.225 .726 & 13,8 \\
\hline & Centro-Oeste & 11.856 .109 & 11.090 .777 & 765.332 & 6,5 & 1.905 .464 & 16,1 \\
\hline \multirow{2}{*}{ Localização } & Urbana & 136.557 .948 & 127.952 .695 & 8.605 .253 & 6,3 & 19.886 .023 & 14,6 \\
\hline & Rural & 22.685 .422 & 18.120 .333 & 4.565 .089 & 20,1 & 8.143 .345 & 35,9 \\
\hline \multirow{2}{*}{ Sexo } & Masculino & 76.000 .191 & 69.438 .923 & 6.561 .268 & 8,6 & 13.871 .114 & 18,3 \\
\hline & Feminino & 83.243 .179 & 76.634 .105 & 6.609 .074 & 7,9 & 14.158 .254 & 17,0 \\
\hline \multirow{4}{*}{ Raça/Cor } & Branca & 73.416 .161 & 69.716 .766 & 3.699 .395 & 5,0 & 9.476 .573 & 12,9 \\
\hline & Negra & 84.348 .125 & 74.985 .165 & 9.362 .960 & 11,1 & 18.310 .141 & 21,7 \\
\hline & Amarela & 873.936 & 852.714 & 21.222 & 2,4 & 83.832 & 9,6 \\
\hline & Indígena & 604.335 & 518.383 & 85.952 & 14,2 & 158.009 & 26,1 \\
\hline
\end{tabular}

Fonte: Pnad, 2014. Elaboraçăo: Gabinete Secadi

Essa tabela publicada no documento referência (BRASIL, 2016), apresentado pelo Ministério da Educação num seminário em Brasília no primeiro semestre de 2016, reforça o tamanho do desafio frente a realidade de mais de 40 milhões de brasileiros que ainda permanecem na condição de analfabetismo, seja ele absoluto ou funcional. Os dados também revelam que esse analfabetismo tem cor, classe social e território. Não desconsiderando tudo o 
que se realizou no país nos últimos 20 anos, sob a vigência da Lei de Diretrizes e Bases da Educação Nacional no 9.394/1996, em termos de educação de jovens e adultos, precisamos reconhecer que ainda estamos longe da garantia da educação como Direito de Todos.

Constatar essa dura realidade nos convoca a pensar o que estamos fazendo nesse país no campo da Educação de Adultos. Não na expectativa de buscar culpas e culpados, mas para entender um pouco mais dessa realidade, conhecendo o que foi feito, analisando o caminho, para poder reconhecer equívocos e para, em seguida, retomar a rota.

\title{
O QUE JÁ FOI FEITO EM EDUCAÇÃO DE ADULTOS NO BRASIL
}

Mais uma vez, o impulso a partir do contexto da realidade brasileira nos provoca a retomar a história, sobretudo porque,

\begin{abstract}
A destruição do passado - ou melhor, dos mecanismos sociais que vinculam nossa experiência pessoal à das gerações passadas - é um dos fenômenos mais característicos e lúgubres do final do século XX. Quase todos os jovens de hoje crescem numa espécie de presente contínuo, sem qualquer relação orgânica com o passado público da época em que vivem. (HOBSBAWM, 1995, p.13)
\end{abstract}

Em contextos tão adversos, como os que estamos vivendo nos últimos dois anos no Brasil, em que a realidade parece não dar conta de nos ajudar a ver saídas, é sem dúvidas nesses momentos em que essa a retomada da história do vivido se faz tão necessária. Portanto, voltar ao que o país já fez em Educação de Adultos, como a pensou, implementou e como a vemos hoje é fundamental para desconstruir qualquer visão fatalista de história. É também uma oportunidade para ajudar a juventude a conhecer o passado que construímos e percebam os desafios dessa contínua construção e reconstrução da história.

Aqui gostaria de ampliar um pouco a reflexão de Hobsbawm, pois creio que na Educação de Adultos não sofremos apenas com o presentismo dos jovens, mas também com aqueles dos profissionais que nunca havia atuado na EJA e passaram a ter essa oportunidade nos últimos 20 anos, quando essa passou a ser uma modalidade da educação básica, ou ainda com as políticas implementadas a partir de 2003, com os inúmeros programas que se criou para atender da alfabetização aos cursos técnicos integrados. A mobilização de alfabetizadores, mas sobretudo de professores em contratos temporários ou em concursos efetivos não se seguiram em todos os casos a uma consciência concreta do que representa ser um educador de adultos, ou de jovens e adultos. O mínimo que se pode fazer é, pelo menos, entender o caminho percorrido no Brasil para essa área, para entender que não é necessário "inventar a roda", muito já foi feito e precisamos seguir fazendo. O convite é retomar parte desse história. 
Começo retomando quem fez a História da Educação de Adultos nesse país, nas suas mais diversas acepções e contexto. Começo com Paschoal Lemme, com sua importante tese sobre o "Educação de Adultos", monografia apresentada ao Ministério de Educação e Saúde (MES), por ocasião do concurso público no qual concorreu ao cargo de técnico em educação, em 1938. Neste texto, Lemme apresenta a expressão educação de adultos tendo um tríplice conteúdo,

a) educação sistemática, escolar, para os indivíduos que atingiram a maturidade, no sentido de lhes dar os instrumentos considerados necessários para o desempenho de sua atividade social, no mais amplo sentido;

b) educação sistemática complementar que corrige essa ação escolar e fornece os elementos que a escola não pode proporcionar, no sentido de uma melhor adaptação a condições sociais do indivíduo, não consideradas antes e também a novas formas de atividade;

c) educação supletiva para os indivíduos que, por qualquer circunstância, não puderam sofrer a ação das instituições consideradas normais e fundamentais e que necessitam adquirir técnicas elementares, continuar seu aprendizado ou se aperfeiçoar em qualquer forma de atividade. (LEMME, 2004, p. 45)

As reflexões que realiza neste estudo, iniciando por apresentar os fundamentos sociais e psicológicos da educação de adultos, a educação de adultos no Brasil e, por fim a reflexão sobre uma experiência de cursos de continuação, aperfeiçoamento e oportunidade realizada no Distrito Federal ${ }^{1}$, reiteram sua convicção inicial de que,

Educação, no sentido mais lato, compreende todas as formas de modificação do comportamento humano, considerado quer do ponto de vista individual, quer do ponto de vista coletivo.

O homem, individualmente, educa-se permanentemente, e, através dos tempos, no desenvolvimento da espécie, veio se educando e continua a se educar ininterruptamente. (LEMME, 2004, p.43)

Contemporâneo, porém com visão de educação de adultos bem diferenciada de Lemme, está Lourenço Filho, coordenador da Campanha de Educação de Adolescentes e Adultos (CEAA), a primeira grande movimentação promovida pelo Estado Brasileiro, criada e coordenada pelo então Ministério da Educação e Saúde, que começa em 1947 e é bastante influente até meados dos anos 1950. Esta iniciativa vai ocorrer no contexto em que os dados do Censo Populacional de 1940 já apontavam 56\% da população maior de 15 anos como analfabetos absolutos. Esse dado era utilizado pelos políticos como sendo a expressão do atraso do país, com uma clara culpabilização das mazelas do país ao nível de formação dos brasileiros.

Beisiegel (2008), vai afirmar que a CEAA,

Tinha por Objetivo levar a "educação de base" ou a "educação fundamental comum" a todos os brasileiros iletrados, nas cidades e nas áreas rurais. (...) A

1 Paschoal Lemme, em 14 de fevereiro de 1936, foi detido em seu gabinete de trabalho, permanecendo preso durante ano e meio, e respondendo a processo perante o Tribunal de Segurança Nacional sob a acusação de ter organizado cursos para operários na União Trabalhista, 
educação de base era entendida como o processo educativo "destinado a proporcionar a cada indivíduo os instrumentos indispensáveis ao domínio da cultura de seu tempo, em técnicas que facilitassem o acesso a essa cultura - como a leitura, a escrita, a aritmética elementar, noções de ciências, de vida social, de civismo, de higiene - e com as quais, segundo suas capacidades, cada homem pudesse desenvolver-se e procurar melhor ajustamento social”. (p. 28-29)

É certo que vivemos intensos anos, das décadas de 1940 a 1960, com uma forte ênfase em Educação de Adultos como sinônimo de campanhas de alfabetização, com a visão de que a realidade de atraso econômico e cultural, tinha relação direta com a incapacidade dos indivíduos em superar sua condição de analfabetismo. Mas, será que essa era a única forma de ver e pensar na Educação de Adultos no Brasil? A história mostra que não. Segundo Fávero e Mota (2015) ${ }^{2}$,

Nos anos 1960, criou-se um dito, que representava uma nova postura: o problema não era o analfabetismo e alfabetizar não era a solução. $\mathrm{Na}$ verdade, o problema era a miséria do povo, o meio rural sem escolas ou com um arremedo delas. Essa postura teve sua origem no relatório apresentado pela representação de Pernambuco, da qual fazia parte Paulo Freire, no $2^{\circ}$ Congresso Nacional de Educação de Adultos, realizado no Rio de Janeiro em 1958, e está na base do Sistema de Alfabetização criado por Paulo Freire. (FAVERO e MOTA, 2015, DVD1)

Aproveito essa citação de Osmar Fávero para destacar o importante trabalho que está realizando no Núcleo de Estudos e Documentação sobre Educação de Jovens e Adultos NEDEJA, da Faculdade de Educação da Universidade Federal Fluminense - UFF, com a publicação da pesquisa em três DVDs sobre Educação Popular e Educação de Jovens e Adultos. Um tratamento documental digitalizado de 1.157 documentos, correspondendo a 59.164 páginas, ocupando o espaço de 20 gigabytes.

Esse acervo compreende projetos, programas e propostas de Educação de Jovens e Adultos - EJA, documentos instituidores de campanhas e movimentos, relatórios de experiências, depoimentos, entrevistas, livros, artigos, periódicos, teses, dissertações, monografias e, especialmente, material didático (cartilhas, livros de leitura, vídeos, fotos, slides, folhetos de cordel, entre outros). Muitos desses materiais são exemplares raros, originais ou únicos, recolhidos em arquivos particulares; vários documentos salvos do pouco apreço à preservação de nossa memória ou que sobreviveram à desestruturação dos movimentos populares ocorrida no país particularmente após o golpe militar de 1964. (FÁVERO e MOTA, 2015, Apresentação da Coleção.)

Outra referência nessa produção sobre Educação de Adultos no Brasil é a pesquisadora Vanilda Paiva que desde o primeiro ano de publicação de seu Livro: Educação Popular e Educação de Adultos, em 1972, até sua atualização nos anos 2000, apresenta várias das iniciativas e desafios

2 O DVD I desta publicação já encontra-se disponível no Portal dos Fóruns de EJA (www.forumeja.org.br/educacaopopular), os DVDs II e III estão e processo de disponibilização no mesmo portal. 
que a EJA tem enfrentado na realidade brasileira. Das escolas noturnas do ano de 1860 às experiências consolidadas pós aprovação da Lei de Diretrizes e Bases da Educação Nacional $n^{\circ}$ 9394/96, muito se tem a dizer sobre Educação de Adultos no país.

Trazer essas memórias e reverências, não para desconsiderar o peso do debate internacional sobre o tema, e o quanto ele influencia as políticas públicas de educação no Brasil, sobretudo as ações de alfabetização de adultos. Mas, reitero que há algo a ser dito pelo Brasil sobre o tema, ou seguimos ignorando que Paulo Freire é o educador brasileiro mais traduzido e lido fora do país, com a sua obra Pedagogia do Oprimido já tendo atingido a publicação em mais de 25 idiomas? Claro que aqui estou me referindo a educadores, não a nossos brilhantes representantes da literatura e muito menos a manuais de autoajuda.

A obra de Paulo Freire ${ }^{3}$ representa na História da Educação de Adultos no Brasil um divisor de águas, não pelo seu ineditismo na reflexão das relações de classe social e educação, pois isto já estava presente em Paschoal Lemme. Mas, pela sua defesa inconteste da educação como um ato político. É daqui que desejo seguir, nesta reflexão, em tempos tão difíceis de uma conjuntura educacional brasileira à beira de um colapso real, onde os temas: Escola sem Partido, "Ideologia de Gênero", Militarização das escolas, descaracterização do Ensino Médio, Desvinculação orçamentária, deslegitimação do Fórum Nacional de Educação, inviabilização da Conferência Nacional de Educação, precarização da carreira docente via implantação das Organizações Sociais (OSs) na educação, já não estão mais no discurso, mas se implementam à "velocidade da luz" nas redes públicas municipais e estaduais de ensino pelo país afora.

A preocupação sobre vários desses temas vem sendo reiterada por todos os participantes desse colóquio e não poderia ser diferente, pois estamos vivendo no país uma política de desmonte da educação pública, legitimada por leis e decretos espúrios, publicados por um poder executivo ilegítimo e por um poder legislativo, no mínimo de caráter ético duvidoso, dadas as inúmeras denúncias de recebimentos de propinas vindas, não só do empresariado e de representantes do capital especulativo, mas das negociatas do orçamento federal, para a manutenção dessa lógica de um presidencialismo de coalizão, que há muito impera na nossa república federativa. Uma república federativa onde nunca se pode sequer contar com uma justiça cega, no sentido do exercício do poder judiciário independente de quem fosse o réu. No Brasil que se revela hoje ao mundo, talvez a única questão que se alguém duvidava, a luz do dia tem deixado muito evidente é que somos um país de enormes injustiças sociais e cujos representantes do Poder Judiciário elegem exatamente a cor das pessoas e a cor das bandeiras que condena.

3 Só para indicar as que já estão em domínio público e dialogam diretamente com o tema dessa reflexão, podemos encontrar no site do Fórum de EJA, em http://forumeja.org.br/node/1163 :FREIRE (1967, 1981, 1983, 1987, 1989, 1996, 2001). 
É nesta conjuntura que cabe retomar, embora com certo "pessimismo da inteligência, [porém, com] otimismo da vontade", a discussão sobre Educação de Adultos no Brasil no século XXI. Talvez, o mais justo seja retroceder ao final dos anos 1980 e início dos anos 1990, quando depois do retorno de muitos militantes da educação, caçados pela Ditadura Militar, inclusive Paulo Freire, as questões urgentes que estavam ligadas a redemocratização no país.

A participação efetiva desses militantes da educação popular (professores universitários, estudantes secundaristas e universitários, religiosos), em partidos políticos do campo democrático popular, sindicatos e movimentos e organizações sociais que retomavam muitos dos referenciais políticos e pedagógicos freirianos, sobretudo no que concerne a defesa de propostas de uma educação transformadora. Mas transformar o quê? Naquele contexto pós Ditadura Militar representava transformar as relações entre educador/educando; as formas de oferta da educação para jovens e adultos trabalhadores; as formas de tratar a relação escola/sociedade, pois sem essas mudanças básicas, não se poderia pensar em reconquistar os jovens e adultos trabalhadores para a volta a escolarização e para a garantia do direito a educação básica.

São inúmeras as experiências realizadas na década de 1980 a 2000, nesse caminho de fortalecimento de uma proposta de EJA como garantia de Direito. Poderia aqui listar inúmeras realizadas em estados, municípios, no Distrito federal, e mesmo pela União no processo de redemocratização do país, tais como a extinção do MOBRAL e criação da Fundação Educar na metade da década de $1980^{4}$; a consolidação dos Fóruns de EJA e das primeiras experiências municipais de EJA; a continuidade de implementação de ações de alfabetização, em nível nacional, em campanhas como Programa Alfabetização Solidária; a manutenção da escolarização precária nas classes de Ensino Supletivo, que marcam as últimas décadas de 1990; passando para os inúmeros programas inaugurados pelas políticas federais nos governos Lula e Dilma a partir de 2003.

No contexto do governo federal, onde estiveram à frente o Partido dos Trabalhadores (2003 a 2015), a lista dos Programas se alarga e costumo dizer que alguns desses PRÓ podem ter se tornando CONTRA a consolidação efetiva de EJA como política pública: Programa Brasil Alfabetizado, Programa Fazendo Escola, Programa Nacional de Inclusão do Jovens (Projovem), Programa Nacional de Integração da Educação Profissional com a Educação Básica, na modalidade de Educação de Jovens e Adultos (Proeja), Programa Saberes da Terra, Programa Nacional de Acesso ao Ensino Técnico e Emprego (Pronatec)... Claro que, nesse contexto de execução orçamentária que se materializa por meio de ações e programas, não desconsideramos o

4 Os documentos da Fundação Educar até os anos 1990 são os primeiros a registrar a expressão Educação de Jovens e Adultos, que será retomada em 1996 com a aprovação da LDB no 9394/1996. 
papel fundamental dos aportes de recursos que foram implementados pela via desses programas, mas é preciso avaliar os resultados desses investimentos.

Não é possível ainda desconsiderar a importância que assume a interlocução do governo federal, para a construção da política de EJA, com a Comissão Nacional de Alfabetização e Educação de Jovens e Adultos (Cnaeja) ${ }^{5}$. Com especial destaque para a interlocução com os Fóruns de EJA do Brasil, com os intensos debates sobre a temática durante as conferências nacionais (Conae/2010 e Conae/2014), culminando com a aprovação da Lei 13005/2014 do Plano Nacional de Educação 2014-2024 ${ }^{6}$. Tudo isso, nos faz voltar a pergunta onde está mesmo a Educação de Jovens e Adultos nessa conjuntura?

Do ponto de vista legal, desde 1996 passou da denominação Ensino Supletivo à de Educação de Jovens e Adultos, entendida como modalidade da Educação Básica. Do ponto de vista financeiro, saiu da invisibilidade no Fundo de Manutenção e Desenvolvimento do Ensino Fundamental (Fundef) para a inclusão excludente no Fundo de Manutenção e Desenvolvimento da Educação Básica e Valorização do Magistério (Fundeb). Do ponto de vista político está em evidência em pelo menos 4 metas do PNE 2014-2024 (3, 8, 9 e 10). Do ponto de vista social, ressalvadas algumas experiências localizadas, creio que ainda é vista como uma forma aligeirada e compensatória de escolarização, não apenas pelos políticos, gestores, mas ainda por educadores e educandos. Mudamos o nome, mas não alteramos de forma hegemônica as práticas e as concepções.

Dito isso, é preciso reconhecer que a educação de adultos foi e segue sendo um grande desafio, os dados de matrícula, comparando a situação do ano de 2006 e 2014 o demonstram abaixo,

\begin{tabular}{|c|c|c|c|}
\hline & 2006 & $2014^{*}$ & Variaçào \\
\hline EJA - Fundamental (semipresencial / presença flexivel) & 349.404 & 170.003 & $-51,30 \%$ \\
\hline EJA - Ensino médio (presencial) & 1.345 .167 & 1.000 .010 & $-25,70 \%$ \\
\hline EJA - Ensino médio (semipresencial / presença flexível) & 405.497 & 266.161 & $-34,40 \%$ \\
\hline $\begin{array}{l}\text { Ensino regular } 5^{a} \text { a } 8^{a} \text { séries (alunos com } 18 \text { anos ou } \\
\text { mais) }\end{array}$ & 1.091 .561 & 289.064 & $-73,50 \%$ \\
\hline Ensino regular médio (alunos com 25 anos ou mais) & 640.536 & 199.007 & $-68,90 \%$ \\
\hline $\begin{array}{l}\text { Ensino profissional / nivel médio (alunos com } 25 \text { anos ou } \\
\text { mais) }\end{array}$ & 276.685 & 581.303 & $110,10 \%$ \\
\hline Educação especial / EJA & 36.953 & 111.963 & $203,00 \%$ \\
\hline
\end{tabular}

Fonte: Censo Escolar da Educação Básica. Inep, 2014

* A partir de 2007 , o Censo Escolar da Educaçáo Básica passou

5 Para uma análise mais detida desse contexto acesse Periódico do INEP Em Aberto no 82, disponível em: http://emaberto.inep.gov.br/index.php/emaberto/issue/view/245

$6 \quad$ Um balanço dessas políticas está disponível no Documento Nacional Confintea+6, já mencionado (BRASIL, 2016), disponível em: http://forumeja.org.br/sites/forumeja.org.br/files/documento_nacional_6confintea_final.pdf 
Observando os dados que estão relacionados ao final do primeiro mandato do Presidente Lula e ao início do segundo mandato da Presidenta Dilma, constatamos que houve redução de matrícula em todas as formas de oferta da EJA no Brasil, exceto na oferta da EJA integrada a Educação Profissional (EP) e na EJA vinculada a Educação Especial. Os dois casos poderiam ser passíveis de comemoração, só que não. Na realidade a ínfima matrícula na integração com EP, tem relação com as matrículas obrigatórias do Proeja, que como todos sabem, inclusive neste Instituto que nos recebe para esta atividade, sobrevivem a duras penas as pressões dentro dessa rede.

Quanto a matrícula na Educação Especial cabe reconhecer que ela representou o esforço da política de inclusão no país, que encaminhando o fechamento das turmas de escolarização que funcionavam nas Associações de Pais e Amigos dos Excepcionais (APAEs), obrigou os sistemas de ensino a receberem os alunos nas classes de EJA. A grande questão é que, da forma como essa matrícula foi transferida para as escolas, em sua maioria municipais, a chegada desses alunos acabou por representar quase que turmas exclusivas de EJA com alunos especiais, o que é contraditório ao que defende a política de inclusão. $\mathrm{O}$ que se agrava mais com a não preparação dos professores da EJA para lidarem com as especificidades dos educandos especiais.

Voltando aos dados da redução da matrícula, esses precisam ser o tempo todo relacionados com o da demanda a ser atendida. Por isso é importante olhar a realidade atual, os dados de 2016 da Pnad/IBGE, conforme Tabela 3 para pensar o que ainda temos a fazer.

\section{Tabela 3 - Porcentagem do nível de ensino na Educação Básica por grupos de idade}

\begin{tabular}{|c|c|c|c|c|c|}
\hline Grupos de idade & $\begin{array}{c}\text { Sem } \\
\text { instrução }\end{array}$ & $\begin{array}{c}\text { Fundamental } \\
\text { incompleto }\end{array}$ & $\begin{array}{c}\text { Fundamental } \\
\text { completo }\end{array}$ & $\begin{array}{c}\text { Médio } \\
\text { incompleto }\end{array}$ & $\begin{array}{c}\text { Médio } \\
\text { completo }\end{array}$ \\
\hline 25 a 34 anos & 3,1 & 17,0 & 9,3 & 7,1 & 38,9 \\
\hline 35 a 44 anos & 6,0 & 28,0 & 10,5 & 4,7 & 31,1 \\
\hline 45 a 54 anos & 9,5 & 33,1 & 10,6 & 3,8 & 25,6 \\
\hline 55 a 64 anos & 14,5 & 42,1 & 10,4 & 2,0 & 17,7 \\
\hline 25 a 64 anos & 7,6 & 28,7 & 10,2 & 4,7 & 29,6 \\
\hline 65 anos ou mais & 29,9 & 45,5 & 6,7 & 0,9 & 9,3 \\
\hline
\end{tabular}

Fonte: PNAD/IBGE (2016). Elaboração: Profo Ricardo Antonio Gonçalves Teixeira - FE/UFG

Mais do que propor soluções, o que penso que precisamos fazer é, de novo, olhar para a história, sobretudo a história recente dos últimos 20 anos e nos perguntarmos o que fizemos? Como fizemos? Por que fizemos? Os resultados obtidos contribuíram na efetivação do direito a educação dos adultos, dos jovens? Parto de duas realidades que estamos presenciando no contexto atual e que revelam algumas das saídas que vem sendo encontradas para EJA: realidade da transformação de toda matrícula do Ensino Médio Noturno em Goiás para um programa chamado 
PROFEN (Programa de Fortalecimento do Ensino Noturno), que concretamente é a retirada da matrícula como ensino "regular", e uma pseudonova forma de fazer EJA (reconhecimento da modalidade? Não. Estratégia para escapar da avaliação IDEB) e a organização de escolas polo ou nucleações, para justificar o fechamento das escolas de EJA (exemplo de Porto Alegre).

\section{PARA CONTINUAR PENSANDO}

Todas essas reflexões nos colocam muitas indagações para seguirmos pensando os desafios para EJA. Reitero que para manter o "otimismo da vontade", precisamos enfrentar o "pessimismo da inteligência". É o que tentei fazer aqui e nas publicações de balanço dos últimos 20 anos da EJA, após a aprovação da Lei 9394/96. Indico aos leitores uma dessas reflexões que se encontra num artigo na revista Retratos da Escola, da CNTE, de dezembro de 2016,disponível em http://www.cnte.org.br/images/stories/retratos_da_escola/retratos_da_escola_19_2016.pdf

As questões levantadas são para reiterar nossa perspectiva de que muito fizemos na Educação de Adultos, na EJA, nesse país e que muito ainda temos a fazer e espero que compartilhem comigo dessa visão. Para finalizar gostaria de indicar mais uma vez a reflexão de Hobsbawm, analisando o chamado brevíssimo Século XX, em sua autobiografia, o livro chamado Tempos Interessantes - uma vida no Século XX, que ele encerra diante de todos os desafios com a seguinte frase: "Mesmo assim, não nos desarmemos, mesmo em tempos insatisfatórios. A injustiça social ainda precisa ser denunciada e combatida. O mundo não vai melhorar sozinho." (HOBSBAWM, 2002, p. 455)

\section{REFERÊNCIAS}

BEISIEGEL. Celso de Rui. (2004). Estado e educação popular - Um estudo sobre a educação de adultos. 1a reedição. Brasília: Liber Livro.

BEISIEGEL. Celso de Rui. (2008). Política e educação popular: a teoria e a prática de Paulo Freire no Brasil. Brasília: Líber Livro.

BRASIL. (2016). Ministério da Educação. Secretaria de Educação Continuada, Alfabetização, Diversidade e Inclusão. Documento Nacional Preparatório à VI Conferência Internacional de Educação de Adultos: versão atualizada Confintea Brasil+6. Brasília. Disponível em: <http://unesdoc.unesco.org/images/0024/002446/244673POR.pdf>. Acesso em: 05 set. 2016.

CONFERÊNCIA INTERNACIONAL DE EDUCAÇÃO DE ADULTOS. (1999). (V: 1997, Hamburgo, Alemanha). Declaração de Hamburgo: agenda para o futuro. Brasília: SESI/UNESCO 
CURY, Carlos Roberto Jamil. (2010). Carlos Roberto Jamil Cury - intelectual e educador. Organização e Introdução Cynthia Greive Veiga. Belo Horizonte: Autêntica. (Coleção Perfis da Educação).

FÁVERO, Osmar e MOTA, Elisa (Orgs.). (2015). Educação popular e educação de jovens e adultos. Recurso Eletrônico. 1 ed. Petrópolis: De Petrus e Alli; Rio de Janeiro: FAPERJ.

FREIRE, Paulo. (1967). Educação como Prática da Liberdade. Rio de Janeiro: Paz e Terra.

FREIRE, Paulo. (1981). Ação Cultural para a Liberdade. 5a Ed. Rio de Janeiro: Paz e Terra.

FREIRE, Paulo. (1983).Extensão ou Comunicação. 5a Ed. Rio de Janeiro: Paz e Terra.

FREIRE, Paulo. (1987).Pedagogia do Oprimido. 17a Ed. Rio de Janeiro: Paz e Terra.

FREIRE, Paulo. (1989).A importância do ato de ler: em três artigos que se completam. São Paulo: Autores Associados: Cortez. (Coleção polêmicas do nosso tempo; 4).

FREIRE, Paulo. (1996).Pedagogia da Autonomia: saberes necessários à prática educativa. São Paulo: Paz e Terra.

FREIRE, Paulo. (2001). Política e Educação: ensaios. 5a Ed. São Paulo, Cortez. (Coleção Questões de Nossa Época; v.23)

HOBSBAWM, Eric. (1995). Era dos Extremos - O breve século XX 1914-1991. São Paulo: Companhia das letras.

HOBSBAWM, Eric. (2002).Tempos interessantes - uma vida no século. São Paulo: Companhia das letras.

LEMME, Paschoal. (2004). Memórias de um educador - Paschoal Lemme. 2 ed. Brasília: INEP. (Vol. 5)

PAIVA, Vanilda. (2003). História da Educação Popular no Brasil - Educação popular e Educação de Adultos. 6 ed. São Paulo: Edições Loyola.

RIBEIRO, Darcy. (1995). O Povo Brasileiro - A formação e o sentido do Brasil. São Paulo: Companhia da Letras.

UNESCO. (2010). Marco de Belém. VI Conferência Internacional de Educação de Adultos. Brasília: Unesco. 